\title{
Strategies for Engaging Men as Anti-Violence Allies: Implications for Ally Movements
}

\author{
Erin Casey
}

\begin{abstract}
As ally movements become an increasingly prevalent element of social justice efforts, research is needed that illuminates effective strategies to initially engage members of privileged social groups in anti-oppression work. This study presents descriptive findings regarding ally engagement strategies and barriers from a qualitative study of a particular ally movement - male anti-violence against women activism. Twenty-seven men who recently initiated involvement in an organization or event dedicated to ending sexual or domestic violence were interviewed regarding their perceptions of effective approaches to reaching and engaging other men in anti-violence work. Participants viewed tailored engagement strategies that tap into existing social networks, that allow men to see themselves reflected in anti-violence movements, and that help men make personal, emotional connections to the issue of violence as most effective. Implications for engaging men in the project of ending violence against women, and for ally movements more generally are discussed.
\end{abstract}

Keywords: Ally development, engaging men, domestic violence, sexual assault, prevention

\section{INTRODUCTION}

Ally movements are predicated on the notion that institutionalized oppression will persist until members of "dominant" social groups become actively involved in ending it. Of central relevance to Social Work's core values of pursuing social justice and social change, these overlapping anti-racism, anti-heterosexist, and anti-sexism efforts endeavor to engage people who are privileged by oppressive social systems in the project of dismantling those very sources of unearned advantage (Bishop, 2002; Broido, 2000). While significant work has conceptualized processes through which members of "dominant" groups come to recognize their own sources of unearned social privilege (e.g., Helms, 1990), scant research has examined how members of these groups are then best supported in translating this awareness into active engagement in working to disassemble systems of oppression.

This study examines ally engagement through the lens of a particular ally movement - men organizing against violence against women. Given that sexual and domestic violence persist as significant public health crises, and are largely perpetrated by males (Tjaden \& Thoennes, 1998), a consensus is emerging that reducing and preventing violence against women requires the participation of men who can model non-violent behavior, and hold their male peers accountable for sexist or abusive conduct (e.g., Flood, 2005). Like ally movements more generally, however, few studies have taken up the question of what approaches best serve to engage "average" men (i.e., men who do not currently see violence against women as an issue relevant to their lives) as potential anti-

Erin Casey, Ph.D., is an Assistant Professor of Social Work at the University of Washington, Tacoma.

Copyright (C) 2010 Advances in Social Work Vol. 11 No. 2 (Fall 2010), 267-282 
violence allies. The purpose of this study is therefore to present findings from a study of new male anti-violence allies regarding the strategies they perceive to be relevant to other men. Implications of these findings for ally development efforts more broadly will then be discussed.

\section{Men's Anti-violence Organizing Groups}

Men's anti-violence organizations are increasingly prevalent in communities and on college campuses, and typically involve males in violence prevention education, skill building related to responding to disrespectful peer behavior, and mentorship of other boys and men (DeKeseredy, Schwartz, \& Alvi, 2000; Katz, 1995). Inherent in this work is often an effort to build a critical consciousness among men about the prevalence and impact of violence against women, the links between the embodiment of traditional forms of masculinity, male privilege and violence perpetration, and the role of men in addressing other men's abusive behavior (Hong, 2000). Examples of existing programs include the Mentors in Violence Prevention Program (Katz, 1995) and the Men Can Stop Rape program in Washington, DC, whose "Men of Strength" (MOST) clubs provide adolescent and young adult men the opportunity to critically interrogate notions of masculinity and to enhance their capacity to take a more active stance against male violence (Men Can Stop Rape, 2010). A non-experimental evaluation of MOST club participants found that high school aged boys reported a greater willingness to intervene to stop a peer's inappropriate behavior after 16 weeks of club participation (Hawkins, 2005).

Although some evidence is emerging about the impact of involvement in antiviolence programs, little is known about the nature or effectiveness of the strategies employed to encourage men's initial participation. A handful of studies have examined factors associated with individual men's decisions to become involved in anti-violence work. These factors include sensitization to or personal experience with the issue of violence (Casey \& Smith, 2010; Coulter, 2003), peer mentorship or support for involvement (Coulter, 2003), a pre-existing social justice consciousness regarding other issues of oppression (Funk, 2008), and concrete involvement invitations that highlight men's strengths and potential contributions (Casey \& Smith, 2010). These factors may therefore also be relevant to ally outreach and engagement strategies. Indeed, evidence from studies of racial ally development suggest that anti-racism involvement is precipitated by exposure to and reflection about race-based oppression, as well as personal connection with mentors and peers who both model ally behavior and invite active participation (Reason, Roosa-Millar, \& Scales, 2005). Finally, numerous antiviolence scholars and practitioners have also suggested the importance of using positive engagement strategies that approach men as having a critical role to play in solving violence, rather than approaching men as potential perpetrators or "part of the problem," a method that is likely to foster defensiveness and disengagement (Berkowitz, 2002; Flood, 2005).

Findings from efficacy studies regarding sexual and domestic violence prevention education may also provide hints about elements of effective ally engagement. Although not directly addressing initial outreach strategies for getting men "in the door," these 
findings highlight possibly compelling characteristics of engagement programs for men. For example, consensus is emerging within prevention research that single sex (Brecklin \& Forde, 2001), male-facilitated (Kilmartin, 2001) prevention programming is more effective in changing men's attitudes than is co-educational programming. Additionally, culturally-tailored efforts that match presentation content to and employ facilitators from within audiences' cultural communities are associated with greater resulting attitude change (Heppner, Neville, Smith, Kivlighan, \& Gershuny, 1999). Thus, initial ally engagement techniques which are facilitated by and for men and are culturally relevant may hold greater appeal for potential allies. Still, these components have not been explicitly examined in relation to efforts to reach out to previously uninvolved men.

\section{Purpose of Study}

In summary, although evidence is emerging about the impact of participation in antiviolence organizations or curricula on men and the factors that predispose men to seek these opportunities, very little research has examined the strategies that may best foster initial interest among and engagement of male allies in particular, or of anti-oppression allies more generally. To this end, this study examines qualitative data from interviews with 27 men who recently initiated membership or involvement in an anti-sexual or domestic violence effort. Specifically, this study aims to 1) describe the strategies perceived by these allies as effective in engaging other men, 2) identify the barriers to reaching out to potential allies, and 3) evaluate the implications of anti-violence men's engagement strategies for ally development efforts more broadly.

\section{METHODS}

\section{Participant Recruitment}

Data for these analyses were drawn from a larger study examining factors that precipitate anti-violence involvement for recently recruited male allies. In accordance with procedures approved by the institution's human subjects committee, respondents were recruited via notices disseminated on several topic-relevant national email listservs, through announcements at relevant community meetings throughout a Northwest state, through leaders of men's anti-violence groups in the Pacific Northwest, and through referrals from participants themselves. Potential respondents contacted the researcher directly, and were screened for eligibility. Participation eligibility criteria included initiating on-going involvement in an anti-violence against women organization, event, or group within the past two years at the time of contacting the researcher, and being a man 18 years or older. Because the primary aim of the larger study was to understand the most current influences on men's entrée into anti-violence involvement (these findings are described elsewhere (Casey \& Smith, 2010)), recent initiation into anti-violence work was included as an eligibility criterion. This eligibility decision was made in consultation with current male activists, who felt that although data exist on factors associated with long-time involvement in anti-violence men's organizations (e.g. Funk, 2008), knowledge about how to attract and engage "new," and more broadly representative 
recruits to the movement is needed. Findings regarding ally engagement presented here therefore reflect the experiences and perceptions of those newly initiated male allies.

\section{Sample}

Forty-three men contacted the study and were screened for eligibility. Of these, 14 reported long-term anti-violence involvement and an additional two did not return consent forms and were therefore ineligible for participation. The final sample consisted of 27 men, ages 20-72. All but one identified as White; one man identified as Latino. Of the 16 men ineligible for the study, five identified as African American, one as Latino and 10 as White. Participants came from all regions of the U.S. Length of involvement in anti-violence work at the time of the interview ranged from one to approximately 30 months (only one participant had been doing anti-violence work more than two years at the time of the interview; this discrepancy resulted from a delay in conducting the actual interview). Participants' involvement in anti-violence work generally fell into two categories. First, 11 of the men (41\%) were post-college aged respondents who worked (3 participants) or volunteered (8 participants) with a domestic and/or sexual violencerelated program, government agency, or partnering men's group. These participants' roles ranged from doing direct advocacy with survivors of violence, to volunteering in a shelter or a prevention education program for youth. The other 16 participants (59\%) were involved in college campus-based organizations in which they were engaged in activities such as facilitating educational presentations for other college students, organizing campus-wide anti-violence awareness events, or designing activities or events aimed at garnering additional male participation.

\section{Data Collection and Analytic Strategy}

Nine participants were interviewed in person and the remaining 18 were interviewed by phone. Interviews varied from 45 to approximately 90 minutes in length and were semi-structured, with general questions designed to elicit information about engagement strategies and barriers, followed by tailored follow-up questions to explore relevant issues in greater depth. Question topics included the nature of men's involvement, their use and perceptions of effective and ineffective strategies for engaging other men, and the barriers they encountered in efforts to reach men. All interviews were digitally recorded and transcribed. Eight participants chose to review and approve the written transcripts of their interviews.

Data were analyzed as transcripts were completed using techniques drawn from grounded theory (Strauss \& Corbin, 1998). Analysis proceeded in two stages using the qualitative analytic software program ATLAS-Ti. Because of the paper's primary focus on engagement, all transcripts were first coded by two researchers for general domains, with like domains pertaining to discussions of engagement grouped together. Next, following techniques described by Charmaz (2006), inductive, line-by-line coding on relevant domains was done with the author using extensive simultaneous memoing to uncover concepts within the data. Particular analytical attention was paid to the dimensions of concepts (Strauss \& Corbin, 1998), such as temporality, notions of "effectiveness," affective components, etc., which were enhanced using a constant 
comparative method both within and between cases. From this comparison, layers of concepts related to both engagement and barriers to engagement were uncovered, which resulted in the construction of a two-tiered framework (see Table 1). Once saturation of concepts was reached, all transcripts were re-read and compared for both confirming and disconfirming cases. Resource constraints did not allow for re-interviewing or theoretical sampling at this point. Trustworthiness was then enhanced in three ways; through review by the second researcher, through six member checks, and through third party checks by two independent readers who evaluated the face validity of concepts and the data used to support them.

\section{RESULTS}

Participants described two tiers of strategy for reaching other men. These layers are summarized in Table 1 and are described in turn below. Counts of the number of participants mentioning each theme are provided to further contextualize the data and to speak to "internal generalizability" (Maxwell, 2010, p. 478), or the validity of concepts based on the degree to which they characterize individuals within the sample vs. subgroups within the sample, vs. the sample as a whole. On the surface, men talked about a variety of ways to gain initial access to men, or create venues for engagement. Secondly, respondents discussed tactics or particular ways of approaching deeper conversations about violence and being an ally that they believe hold promise for connecting with other men. These strategies cut across approaches to "gaining access" and are summarized under the "delivering the message" section in Table 1. At both of these levels of engagement, participants described related barriers or challenges to successfully reaching and connecting with other men.

\section{Gaining Access}

Participants identified a variety of strategies for "getting men in the door," and a majority of respondents had personally implemented more than one. Twenty-one of the men $(78 \%)$ reported that gaining access through personal networks was the most effective approach. This largely occurred through tailored, individual conversations with men in their existing social, family or professional networks. All of the college-based allies endorsed this strategy, while about half of the community-based men mentioned it. Participants identified five additional strategies for gaining access to men (noted below), but many felt that, in isolation, these less personalized approaches are less likely to attract longer term anti-violence involvement among men. Fourteen participants (52\%), mostly college-based allies, reported active involvement in presenting or facilitating educational presentations or regarding dating or sexual violence. Eight allies (30\%) had participated in organizing larger anti-violence community events or in arranging speakers. Five respondents (19\%) took part in staging pledge campaigns (events at which men are encouraged to pledge non-violence or support for ending violence against women), and 5 respondents (19\%) were involved in outreach to male youth. Seven men (26\%) speculated that larger anti-violence media (TV/radio) campaigns are needed to reach men, although only one had experience implementing this kind of effort. A higher percentage of community-based participants endorsed this strategy. As previously noted, 
however, a majority of participants felt that broad, generalized approaches such as media campaigns or large public events are likely to be ineffective at engaging men in a meaningful or longer-term way unless coupled with more personalized opportunities for discussion (see below for further discussion).

Table 1: $\quad$ Proportion of Participants Endorsing Engagement Strategies and Barriers

\begin{tabular}{|c|c|c|c|}
\hline Theme & $\begin{array}{r}\text { College-based } \\
\text { allies (n=16) } \\
\mathrm{n}(\%)\end{array}$ & $\begin{array}{r}\text { Community-based } \\
\text { allies (n=11) } \\
\mathbf{n}(\%)\end{array}$ & $\begin{array}{r}\text { Total } \\
(\mathbf{n}=27) \\
\mathbf{n}(\%)\end{array}$ \\
\hline \multicolumn{4}{|l|}{ Gaining Access Strategies } \\
\hline Using personal networks & $16(100)$ & $5(45)$ & $21(78)$ \\
\hline Educational presentations & $12(75)$ & $2(18)$ & $14(52)$ \\
\hline Community events or speakers & $6(38)$ & $2(18)$ & $8(30)$ \\
\hline Media campaigns & $3(19)$ & $4(36)$ & $7(26)$ \\
\hline Pledge campaigns & $4(25)$ & $1(9)$ & $5(19)$ \\
\hline Outreach to youth & $2(13)$ & $3(27)$ & $5(19)$ \\
\hline \multicolumn{4}{|l|}{ Barriers to Gaining Access } \\
\hline Non-personal approaches & $10(63)$ & $4(36)$ & $15(55)$ \\
\hline Male social privilege & $9(56)$ & $6(54)$ & $15(55)$ \\
\hline Not identifying with the messenger & $8(50)$ & $3(27)$ & $11(41)$ \\
\hline Structural barriers & $5(31)$ & $2(18)$ & $7(26)$ \\
\hline \multicolumn{4}{|l|}{ Delivering the Message } \\
\hline \multicolumn{4}{|l|}{ Meeting men where they are } \\
\hline Tailoring conversations & $8(50)$ & $4(36)$ & $12(44)$ \\
\hline Relevant role models & $5(31)$ & $4(36)$ & $9(33)$ \\
\hline Using masculinity & $3(19)$ & $2(18)$ & $5(19)$ \\
\hline Use of self & $9(56)$ & $2(18)$ & $11(41)$ \\
\hline Strengths-based approach to men & $6(38)$ & $4(36)$ & $10(37)$ \\
\hline Survivor stories & $5(31)$ & $3(27)$ & $8(30)$ \\
\hline Broader conversations & $6(38)$ & $2(18)$ & $8(30)$ \\
\hline Compelling Communities & $2(13)$ & $3(27)$ & $5(19)$ \\
\hline \multicolumn{4}{|l|}{ Barriers to the Message } \\
\hline Perceived negativism toward men & $8(50)$ & $2(18)$ & $10(38)$ \\
\hline Ambivalence about “feminism” & $3(19)$ & $2(18)$ & 5 (19) \\
\hline
\end{tabular}

\section{Barriers to Accessing Men}

Based on their own experiences of attempting to engage other men's interest in antiviolence work, as well as their perceptions of their own past barriers to engagement, participants described a number of factors that they believed prevent men from attending educational or involvement opportunities. These fell into four general themes. First, 15 
respondents (55\%) identified non-personalized approaches as ineffective at reaching other men. These respondents, mostly college-based allies, perceived that generalized strategies such as posting flyers, sending out letters or mass emails, using posters, billboards or media campaigns, or holding broader community events were often unsuccessful at attracting men's attention or attendance. Participants speculated that because many men view sexual or domestic violence as "women's" issues, they are not motivated to engage with materials or messages that raise these issues in a general way. Respondents suggested that without more personal or individualized links to the issue of violence, men are unlikely to notice educational opportunities or to see them as relevant. One participant expressed frustration with multiple attempts to garner male interest for a campus-based men's anti-violence group through advertising campaigns:

I guess our big problem is that even though we can do advertising or send out emails, not many people are willing to sign up, or who knows if they're even reading them because I have no reasons for why they would. We really wanted to get our name out there... but it just didn't work for us. (MAV16)

Second, 15 respondents (55\%) identified male social privilege as a significant engagement barrier. Participants alternatively described this barrier as other men's beliefs that violence against women is not a significant problem or does not apply to men, or as other men's performance of "stereotypical masculinity" that results in minimizing, making light of, or even tacitly perpetuating the problem of sexual or domestic violence. As one participant noted, "A lot of people, you know, they've grown up with this [attitude] their whole lives, and they just don't see anything wrong with it. They think it's just fine... either, 'I just don't want to get involved, this is not my problem,' or 'yeah, that's just a normal thing to do.'” (MAV1) Another participant described male privilege as a tendency and ability to avoid the topic:

I think that me being an older student, and having lived a little bit of life, I know that just about anything that is very honest about the problem turns men off. It's not something we want to admit to. It's not something we want to acknowledge. It's not something that we willingly want to be confronted with. (MAV14)

Next, 11 respondents (41\%) described not identifying with the messenger as a barrier for many men. These participants, a higher percentage of whom were college-based, suggested that the identity, perceived identity, age or "outsider" status of some male antiviolence messengers may have reduced the degree to which they influenced other men or convinced them to attend an event or presentation. One college-based participant shared:

We [men against violence group] had an outsider come in... And one time he came in to kind of rouse the masses, and the second time he came in to kind of pull in everybody else... and it didn't really grab many people. So you know that really didn't work. It didn't really work all that well getting someone who was seen as an expert in the field. (MAV11)

Some speculated that the title of anti-violence or men's organizing groups might not offer a point of connection for many men, or that stereotypes of anti-violence men as 
"liberal," or "soft," deterred men from joining, as evidenced in the following communitybased respondent's comments:

I think that in terms of getting involved in women's issues, one of the hesitations is a lot of guys think the guys that are involved are like my friend... meek, ponytailed, soft-spoken, Birkenstocks.... And they don't want to be associated with that kind of like, asexual, sort of meek stereotype. (MAV3)

Finally, seven participants (26\%) mentioned structural barriers such as a lack of time, lack of an accessible anti-violence group in some men's communities, and lack of support from campus administrations or other social structures as factors in impeding men's antiviolence engagement.

\section{Delivering the Message}

Participants described a variety of specific, intentional approaches to framing messaging about anti-violence work to men. These "delivery" strategies were at the core of what participants identified as strategic and effective approaches to engagement. Six "delivering the message" approaches were described, and are summarized in Table 1.

Meeting men where they're at. The most common set of engagement strategies employed by men in the study was to approach other men in a tailored and individualized way. Comprised of three sub-themes, "meeting men where they're at" is a group of strategies generally intended to allow other men to personally relate to anti-violence efforts or conversations and to build on the knowledge and attitudes they hold at the moment they are engaged. Inherent in this set of strategies was an effort to help a potential ally find a personal point of connection to the issue of violence, or to a compelling "harm" done to him or his loved ones because of the existence of violence. Many of the "meeting men where they're at" strategies seemed to parallel, or perhaps be a response to the barriers to engagement described later in this article.

Tailoring conversations. This first sub-theme in "meeting men where they're at" was reported by 12 respondents (44\%). These participants used an open approach to engaging men individually or in groups that involved asking them questions, assessing their attitudes, learning about them and/or using what they know about the men to frame the way they subsequently engaged in discussion related to the issue of violence. This strategy was reported by half of college-based participants, and about one third of community-based allies. As one participant noted, "I think it's vitally important to listen to where people are at and truly understand where people are coming from because there's no way that we can engage people effectively until we know where they are coming from” (MAV24). For some participants, meeting men where they're at meant literally going to the places men are likely to be - fraternities, elks club, workplaces, etc. Participants endorsing this strategy did not have a prescriptive approach to how they talked about violence with other men, but tailored their conversation to their audience in the moment, such as the approach described by the following participant:

I don't really go in with a set strategy of how I'm going to work with a person. I kind of go in, I feel out the situation, I see what's going on, and we might not 
even get into that first day. It might just be me making friends with them that day and then talking about it at a later point. But I always go back to it. (MAV15)

Relevant role models. Nine respondents (33\%) described the importance of having messengers in their anti-violence group who appeal to, are respected by, or are reflective of the men they are speaking to, so that men could literally "see themselves" in the group. Connected to this is the idea that men should get the message that they don't have to be someone else, or change in order to be involved. Not mentioned in this category by participants, however, was diversity among messengers in terms of race/ethnicity. One respondent described his groups' efforts to appeal broadly to their college peers:

I think it's really important to show that men that are already involved are average, normal people... Because I know that when I had heard presentations before I could never really relate to the person giving the presentation about sexual assault, and it's never someone that I could really see as... similar to me. And so ... we've shown the men on our campus that the men of [anti-violence group] are average Joe type guys. Like they're a lot like you. They like to go out. They've been to a college party before. They have friends, possibly have girlfriends. And it's because of either they know a victim of sexual assault, or they have girlfriends, and they don't want a sexual assault to happen to them is why they get involved. And I think like if you could show men that it's all right to speak up about this subject, more men are going to get involved. (MAV12)

Using masculinity. Finally, five respondents (19\%) described strategies that capitalize on or appeal to "traditional" or stereotypical aspects of masculinity as a way to "meet men where they are." For example, one respondent described using an approach based on his perception that "challenges" appeal to men and draw them in:

... it may even be a cultural stereotype in and of itself, but I think guys tend to... like challenges and respond to them in a positive way for the most part. So if you can sort of frame it in that idea that, 'We don't want you to go against the norm simply for the sake of going against the norm; we want you to step up because this is something that we think is an important issue. Hopefully we've convinced you that it's an important issue, and you know we want to challenge you to be the one to take a stand. (MAV2)

Use of self. The second "delivery" strategy was described by $41 \%$ of participants, a majority of whom were college-based. This approach was generally characterized by participants being open about their own experiences, faults, past "sexist" mistakes, or vulnerabilities in conversations with other men, or by being a visible advocate or role model and demonstrating the kinds of behaviors he is hoping to see in others. One participant described how he allows other men access to his own emotional processing as a way to engage their empathy:

I will kind of just allow myself to become emotional and just say, 'You know today was really rough at the meeting... when we talked about this one woman that was sexually assaulted on our campus.' Or if I get a really intense call on the hotline, you know I'll come back and say... 'I got a call and she was saying 
how her boyfriend is stalking her and how she's scared he's going to become violent towards her.' You know? I do it because I want people to know that those issues are real, and ...they're in front of our face. (MAV28)

A strengths-based approach to men. A common "delivery" strategy was to relay to men that they are a critical ingredient in ending violence against women. Endorsed by 10 respondents (37\%), this strategy is founded on an assumption that men generally want to help, have important strengths to lend, and will be more compelled to become involved if they are approached as "part of the solution" than as the source of the problem. One participant noted:

I think we sometimes believe that men... How can I say this? That men aren't as intelligent about this issue as they really are, and the conversations that I have really show a level of intelligence and a level of integrity that a lot of men have about this issue. And frankly... if you ask a group of men, "What do you guys think about rape and sexual assault," almost every single one of them... will say, 'That's terrible. I would never want that to happen to another person.' And I think that's a real key of starting this kind of work, is that men think sexual assault is a bad thing. (MAV 12)

Exposing men to survivor stories. Eight participants (30\%) felt that hearing stories, either directly or indirectly, from survivors of violence serves as a powerful way for other men to make emotional connections to the issue of violence and its impact. Several men specifically mentioned Take Back the Night rallies as a particularly compelling awareness and recruiting tool. Other venues mentioned by participants for communicating survivor stories included readings, trainings and videos.

Broader conversations: An additional eight respondents (30\%) described organizing trainings, workshops or conversation groups in which education and engagement related to violence was a piece of a larger discussion. These events tackled topics such as sex, dating, masculinity and communication and contextualized issues of violence within these potentially more broadly appealing topics.

Creating compelling communities. Finally, five participants (19\%) talked about being a part of or intentionally fostering groups that others would admire and want to join. For these men, the experience of being in a fun, visible, engaged, mutually supportive community was both a transformative personal experience and a persuasive tool for inviting other men's participation. One participant mused:

Well for me personally, the community aspect of it is unlike anything I've ever had. And that definitely keeps me coming back. It keeps me coming. And it's weird because that was what hooked me in the first place, and I'm still like dumbfounded by this, like really? It's something that just never gets old, that still kind of surprises me that I walk into a room and talk about my feelings with other men. Like that still amazes me. (MAV30) 


\section{Barriers to Message Delivery}

Participants described two primary barriers to men "hearing" anti-violence messaging, or connecting with the engagement strategies employed by respondents. First, 10 respondents (38\%) noted that any strategy with a remotely negative approach to men was ineffective. These mostly college-based participants described negative approaches as dwelling on statistics about the proportion of perpetrators who are male, giving men behavioral “don'ts” to avoid rape, or talking about men's responsibility for the problem, and suggested that these strategies create an environment in which men feel defensive, "bashed," or blamed. Respondents suggested that because most men are not perpetrators, hearing about men as perpetrators may feel inordinately shaming, or make the content seem irrelevant. One participant noted that extra caution is needed to guard against a blaming message to men:

...when people talk about this kind of stuff... to men, [the men] are being made to feel guilty as a man. Like, 'All this sexism exists, and part of it's your fault.' I think that's what a lot of men are hearing. Regardless of whether that's what people say, that's what a lot of men are hearing. (MAV19)

Secondly, five participants (19\%) felt that men's ambivalence about or resistance to "feminism," along with their association of violence against women as a "feminist" issue creates a barrier to seeing the contribution they might make in anti-violence work. Respondents speculated that some men may feel confusion about how to simultaneously negotiate their own masculinity and oppose violence against women, or about how to be active against violence without endorsing everything that they feel "feminists" are proposing. One participant summed up this dilemma:

I think a lot of men are afraid that if they embrace feminism... they're suddenly going to be hypocrites if they still want their wife to please shave her legs. Or if they hold the door for a woman, and that sort of thing. If they look at pornography, you know - ever - they're going to be a big hypocrite. (MAV3)

\section{DISCUSSION AND IMPLICATIONS FOR ALLY BUILDING}

As a vehicle for examining the process of ally recruitment, this study examined strategies identified by male anti-violence allies as potentially effective for reaching out to other men. Across the tactics described by respondents, three themes emerge that hold implications for both the practice of engaging men in anti-violence efforts, and for thinking about ally development projects more generally. Many of these implications are congruent with core tenets of Social Work practice and are described more fully below.

\section{Use of Social Networks}

Across the domains of both gaining access and delivering the message to potential allies, respondents highlighted their belief that reaching men through their existing social networks was more effective than generalized approaches to advertising anti-violence messages. All of the college-based participants and nearly half of the community-based men leveraged their own social, professional and familial ties as a means of reaching out. 
In addition to the relatively easier access allies have to their own social circles, engaging men within personal social networks enhances the probability that potential anti-violence recruits will see the movement as relevant, and will view the "messenger" as credible. This strategy is supported by social psychological evidence that individuals may be more influenced by the perceived beliefs of their closest referents, such as friends and family members than by general norms emerging from their community (Cialdini \& Trost, 1998), as well as by the evidence cited in the introduction to this paper that culturallyrelevant prevention approaches are more effective (Heppner et al., 1999). Further, research suggests that men's own reported willingness to intervene in the disrespectful behavior of other males is related to their perception of their male friends' willingness to do the same (Stein, 2007). Ally building efforts more generally may benefit from leveraging allies' existing social networks as a core strategy for creating personalized and compelling conversations and relationships. Indeed, previous research on social justice ally formation has found that allies' entrée into activism is often predicated on friendships or mentoring relationships with other allies (Broido, 2000; Reason et al., 2005).

However, prioritizing the leveraging of allies' social networks may limit access to groups of potential allies who are outside of the "choir" familiar with anti-violence or anti-oppression movements. Here again, prevention research may be instructive. Popular Opinion Leader approaches (POL) identify and recruit natural, charismatic leaders within specific social networks, who are then trained to initiate conversations and skill building with their friends regarding specific health behaviors. POL approaches have been successfully applied in several fields, including HIV prevention (Fernandez et al., 2003), and may be powerful tools within ally-building to harness the influential power of everwidening circles of social networks.

\section{Starting Where Potential Allies Are}

Like the Social Work mantra of "starting where the client is," participants in this study highlighted the perceived effectiveness of assessing men's current beliefs and attitudes, and of tailoring conversations to an ally's level of violence-related awareness at the time of engagement. This tailored engagement is likely assisted by participants' focus on and perceived success with leveraging their own social networks, as described above. Inherent in this individualized approach was a focus on helping each potential ally to recognize or form a personal connection with the issue of violence against women, in order to foster an emotional commitment to the topic. To do this, study participants used survivor stories, their own experiences, and their knowledge of what is important to the potential ally to personalize their message. Interestingly, although college-based and community based participants endorsed these strategies in somewhat different proportions, all engagement approaches were mentioned by at least some members of both groups, highlighting the importance of tailored efforts.

Participants in this study also echoed the sentiments of anti-violence activists and scholars (e.g.., Berkowitz, 2002) in stressing the importance of strengths-based approaches to men that communicate men's important role in ending violence. Indeed, in previous analyses of this data, and in other research related to social justice ally 
development, a specific, tangible, and tailored involvement invitation is often a necessary pre-requisite to initiating formal ally involvement (Broido, 2000; Casey \& Smith, 2010). All of this suggests that efforts to encourage potential allies to consider involvement likely need to account for and embark from the current set of beliefs with which they are operating. Further, reaching out to potential allies by highlighting their individual strengths and specific potential contributions is likely a compelling element of engagement.

\section{Negotiating Privilege}

Meeting potential allies "where they are" also raises the complication of how and when to assist those allies in confronting their unearned social privilege. Participants in this study, and voices within violence prevention movements more generally (i.e., Flood, 2005), argue for engagement of expanded numbers of men as a way to viably combat violence. This may include men who may identify with or perpetuate problematic aspects of male privilege. Indeed, several of the participants in this study identified male privilege and ambivalence about "feminism" as fundamental barriers to "average" guys becoming involved in anti-violence work. Some of the strategies described by respondents were, concordantly, designed to prevent or deflect male defensiveness related to the issue of violence against women. To overcome these barriers, participants endorsed tailored engagement strategies that highlighted potential male allies' strengths that at times made strategic use of stereotypical masculinity, and that accounted for the current belief system of the men they were approaching. These strategies create a potential tension between the value of "meeting men where they are" and risking reinforcing or reproducing male privilege within anti-violence efforts. Indeed, in conceptual work regarding "aspiring” social justice allies, Edwards (2006) notes that allies who lack an understanding of the underlying systems of inequity that support violence may unknowingly support those very systems by acting to "protect" women rather than working in partnership with them.

Navigating this tension likely requires a "both-and" approach that combines tailored outreach with increasingly pointed opportunities to consider issues of oppression. Similar to the formation of a social justice consciousness (Helms, 1990), ally-formation is apt to be developmental. Ally efforts can incorporate progressive discussions and learning opportunities regarding privilege while simultaneously calibrating specific involvement activities to individual allies' current knowledge and ability, in an effort to avoid possible harm to members of marginalized groups. It may also be important to connect with men both around positive aspects of masculinities as well as around ways that some aspects of stereotypical masculinity constrict their own well-being or relationships. For example, Men Can Stop Rape places an emphasis on generating "counterstories" to dominant, narrow conceptualizations of masculinity, which reframe "strength" in terms of men's contributions towards ending violence and promoting respect. Many current activists also note the importance of building in explicit mechanisms for consulting with and accountability to women and women's organizations (Flood, 2005; Funk, 2008). As a whole, this suggests that ally engagement efforts should simultaneously demonstrate to individuals the need for their unique contributions within social movements, while 
providing progressive opportunities for accountability and for deeper analysis of social inequity.

\section{Limitations}

Study limitations include the racial homogeneity of the study sample. Findings presented here almost exclusively reflect White men's perceptions of anti-violence ally development and the factors relevant to their own ally experiences, which was in part an unanticipated consequence of limiting the sample to recent initiates into anti-violence work. A glaring gap in both the findings presented here, and research about male antiviolence allies more generally remains the experiences of men of color around antiviolence mobilization. The small, self-selected nature of the sample also represents a limitation as findings may represent a sub-group of male anti-violence allies whose experiences may not be more broadly generalizable. Future research with larger, more diverse samples is needed to evaluate the replicability of these findings. Research that empirically evaluates the effectiveness and impact of the various engagement strategies surfaced by respondents is also warranted.

The limitation of the study sample to men who had joined anti-violence efforts within the past two years likely circumscribed the range of engagement strategies discussed by participants, and potentially narrowed the focus to strategies relevant to men who are relatively early in their ally formation process. Long-term activists have very important and perhaps different insight into the outreach strategies they experience as effective, and future research would do well to capture this knowledge. Finally, because this study focused only on men who have successfully been engaged in anti-violence work, the voices of non-involved men and what they might find compelling or unappealing are missing. Additional scholarship focusing on the discriminating factors separating male anti-violence allies from non-involved men may shed light on how to design engagement strategies to maximize effective male participation.

\section{CONCLUSION}

Social justice ally movements are an important component of efforts to dismantle oppressive systems such as pandemic violence against women. Fostering these movements requires an understanding of the strategies that best engage and retain potential allies in the project of understanding and challenging social injustice. Participants in this study of male anti-violence allies surfaced several engagement strategies that hold promise for recruiting other men into the movement. Specifically, respondents perceived that effective strategies are grounded in potential allies' own social networks, are tailored to and reflective of their diverse identities, and help them make personal connections to the issue of violence. Future research will need to more rigorously test the effectiveness of these engagement strategies, both with anti-violence movements and across social justice ally efforts more broadly. 


\section{References}

Berkowitz, A. (2002). Fostering men's responsibility for preventing sexual assault. In P.A. Schewe (Ed.), Preventing violence in relationships: Interventions across the life span (pp. 163-196). Washington, DC: American Psychological Association.

Bishop, A. (2002). Becoming an ally: Breaking the cycle of oppression in people $\left(2^{\text {nd }}\right.$ ed.). Halifax, Nova Scotia: Fernwood.

Brecklin, L. R., \& Forde, D. R. (2001). A meta-analysis of rape education programs. Violence and Victims, 16, 303-321.

Broido, E. M. (2000). The development of social justice allies during college: A phenomenological investigation. Journal of College Student Development, 41, 3-18.

Casey, E. A., \& Smith, T. (2010). “How can I not?” Men’s pathways to involvement in anti-violence against women work. Violence Against Women, 16, 953-973.

Charmaz, K. (2006). Constructing grounded theory: A practical guide through qualitative analysis. Thousand Oaks: Sage Publications.

Cialdini, R. B., \& Trost, M. R. (1998). Social influence: Social norms, conformity and compliance. In D. T. Gilbert, S. T. Fiske, \& G. Lindzey (Eds.), The handbook of social psychology (4 ${ }^{\text {th }}$ ed., pp. 151-192). New York: McGraw-Hill.

Coulter, R. P. (2003). Boys doing good: Young men and gender equity. Educational Review, 55, 135-145.

DeKeseredy, W. S., Schwartz, M. D., \& Alvi, S. (2000). The role of profeminist men in dealing with woman abuse on the Canadian college campus. Violence Against Women, 6, 918-935.

Edwards, K. E. (2006). Aspiring social justice ally identity development: A conceptual model. NASPA Journal, 43, 39-60.

Fernandez, M. I., Bowen, G. S., Gay, C. L., Mattson, T. R., Bital, E., \& Kelly, J. A. (2003). HIV, sex and social change: Applying ESID principles to HIV prevention research. American Journal of Community Psychology, 32, 333-344.

Flood, M. (2005). Changing men: Best practice in sexual violence education. Women Against Violence, 18, 26-36.

Funk, R. (2008). Men's work: Men's voices and actions against sexism and violence. Journal of Intervention and Prevention in the Community, 36, 155-171.

Hawkins, S. R. (2005). Evaluations findings: Men Can Stop Rape, Men of Strength Clubs 2004-2005. Retrieved from www.mencanstoprape.org

Helms, J. E. (1990). Toward a model of White racial identity development. In J. E. Helms (Ed.), Black and White racial identity: Theory, research and practice (pp. 49-66). Westport, CT: Greenwood Publishing. 
Heppner, M. J., Neville, H. A., Smith, K., Kivlighan, D. M., \& Gershuny, B. S. (1999). Examining immediate and long-term efficacy of rape prevention programming with racially diverse college men. Journal of Counseling Psychology, 46(1), 16-26.

Hong, L. (2000). Toward a transformed approach to prevention: Breaking the link between masculinity and violence. Journal of American College Health, 48, 269-279.

Katz, J. (1995). Reconstructing masculinity in the locker room: The Mentors in Violence Prevention Project. Harvard Educational Review, 65, 163-174.

Kilmartin, C. T. (2001). Sexual assault in context: Teaching college men about gender. Holmes Beach, FL: Learning Publications.

Maxwell, J. A. (2010). Using numbers in qualitative research. Qualitative Inquiry, 16, 475-482.

Men Can Stop Rape (2010). The Men of Strength Club. Retrieved from http://www.mencanstoprape.org/usr_doc/MOST_Club_Brochure_\&_Criteria.pdf

Reason, R. D., Roosa-Millar, E. A., \& Scales, T. C. (2005). Toward a model of racial justice ally development. Journal of College Student Development, 46, 530-546.

Stein, J. L. (2007) Peer educators and close friends as predictors of male college students' willingness to prevent rape. Journal of College Student Development, 48, 75-89.

Strauss, A., \& Corbin, J. (1998). Basics of qualitative research: Techniques and procedures for developing grounded theory. Thousand Oaks, CA: Sage Publications.

Tjaden, P., \& Thoennes, N. (1998). Prevalence, incidence and consequences of violence against women: Findings from the National Violence Against Women Survey. Washington, DC: National Institute of Justice.

\section{Author's Note:}

Address correspondence to: Erin Casey, 1900 Commerce, Box 358425, University of Washington, Tacoma, WA 98402. Email: ercasey@uw.edu 